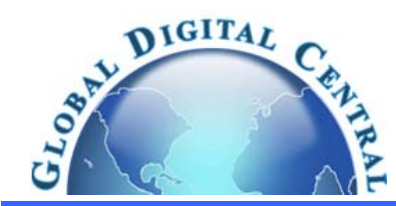

Frontiers in Heat and Mass Transfer

Available at www.ThermalFluidsCentral.org

\title{
EFFECTS OF GEOMETRIC PARAMETERS FOR WAVY FINNED-TUBE HEAT EXCHANGER IN TURBULENT FLOW: A CFD MODELING
}

\author{
Arafat A. Bhuiyan, ${ }^{\mathrm{a}, \mathrm{c}}$, M. Ruhul Amin ${ }^{\mathrm{b}}$, Jamal Naser ${ }^{\mathrm{c}}$, A. K. M. Sadrul Islam ${ }^{\mathrm{a}}$ \\ ${ }^{a}$ Department of Mechanical Engineering, Islamic University of Technology (IUT), Board Bazar, Gazipur-1704, Bangladesh \\ ${ }^{b}$ Department of Mechanical and Industrial Engineering, Montana State University, Bozeman, Montana, MT 59717, USA \\ ${ }^{c}$ Faculty of Science Engineering and Technology (FSET), Swinburne University of Technology, Victoria-3122, Australia
}

\begin{abstract}
In this study, the effects of thermal and hydraulic characteristics of wavy fin and tube heat exchanger are investigated. Simulation has been carried out by a commercial computational fluid dynamics code, ANSYS CFX12.0. The main objective of this study is to investigate the flow characteristics in turbulent flow. Results are predicted for the turbulent flow regime $(2100 \leqslant \mathrm{Re} \leqslant 7000)$ and compared with author's previous work for laminar (400 $\leqslant \mathrm{Re} \leqslant 1200)$ and transitional $(1300 \leqslant \mathrm{Re} \leqslant 2000)$ flow regime. Regarding turbulence, the k- $\omega$ model was used to predict the turbulent flow characteristics with $5 \%$ turbulence intensity. Predicted results were compared with the experimental data for the purpose of validation and the discrepancy is found within $10 \%$ in error range. Parametric study was conducted for different pitches and wavy angles. Flow characteristics obtained for the turbulent range is in line with the pattern observed in laminar and transitional ranges. This study demonstrates a clear understanding and relationship of among different flow ranges and the effects of different geometric parameters on the performance of heat exchanger.
\end{abstract}

Keywords: Wavy fin tube heat exchanger, CFD modeling, Friction factor, Colburn factor, Efficiency index, Reynolds number, Turbulent flow.

\section{INTRODUCTION}

Finned-tube heat exchangers have been extensively used in several automotive applications for various purposes. The performance of heat exchanger is normally dominated by the thermal resistance. The fin geometry has become as increasingly important factor in the design of a plate-and-fin heat exchanger. Typical extended surfaces used for the plate-and-fin heat exchangers are: plain, wavy, offset strip, louvered, perforated and multi-louvered fin have been developed to minimize the thermal resistance. The wavy fin extended surfaces are recognized by the wavy corrugations which boost the heat transfer performance in contrast to the plain plate surfaces. In last decades, several efforts have been devoted to investigate the fundamentals and performance related issues in different experimental works (Kim, Youn et al. 1996, Wang, Fu et al. 1997, Wang 1999, Yan and Sheen 2000, Wang, Hwang et al. 2002, Pirompugd, Wongwises et al. 2006, Junqi, Jiangping et al. 2007, Kim, Ham et al. 2008, Wang, Liaw et al. 2011, Dong, Chen et al. 2012, Dong, Su et al. 2013, Du, Feng et al. 2013, Wu, Wu et al. 2014). Also a number of numerical attempts have been accomplished in 2D/3D analysis (Jang and Chen 1997, Tao, He et al. 2007, Tao, He et al. 2007, Bhuiyan 2010, Bhuiyan, Zaman et al. 2010, Bhuiyan, Islam et al. 2011, Bhuiyan, Islam et al. 2012, Bhuiyan, Amin et al. 2012, Glazar, Trp et al. 2012, Gong, Min et al. 2013, Bhuiyan 2014, Bhuiyan, Amin et al. 2014, Lin, Wang et al. 2014). But most of the earlier works are limited to laminar to transitional ranges (Chu, He et al. 2009, Bhuiyan, Zaman et al. 2010, Bhuiyan, Islam et al. 2011, Bhuiyan, Islam et al. 2012, Bhuiyan, Amin et al. 2012, He, Chu et al. 2013, Bhuiyan, Amin et al. 2014). In this study, simulation results for wavy fin considering different tube arrangements for turbulent flow range will be investigated. This numerical study is a continuation of the author's previous work for laminar flow (Bhuiyan, Islam et al. 2011) and transitional flow (Bhuiyan, Islam et al. 2012) to show the thermal and hydraulic performance of different flow ranges.

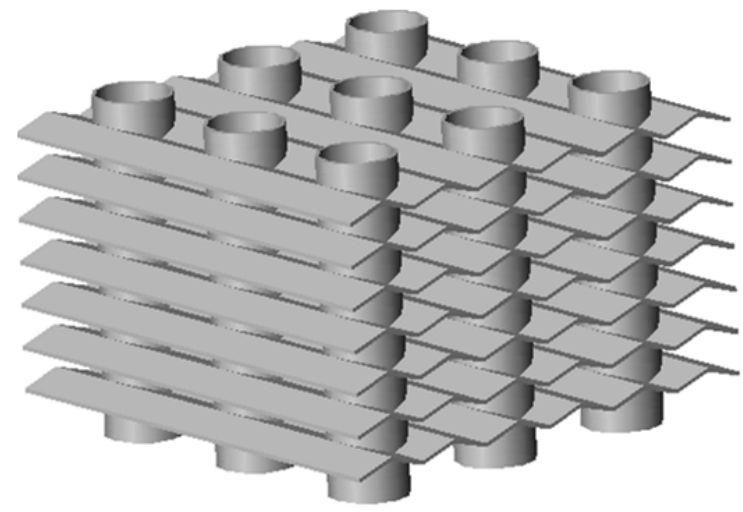

(a) Inlined arrangement

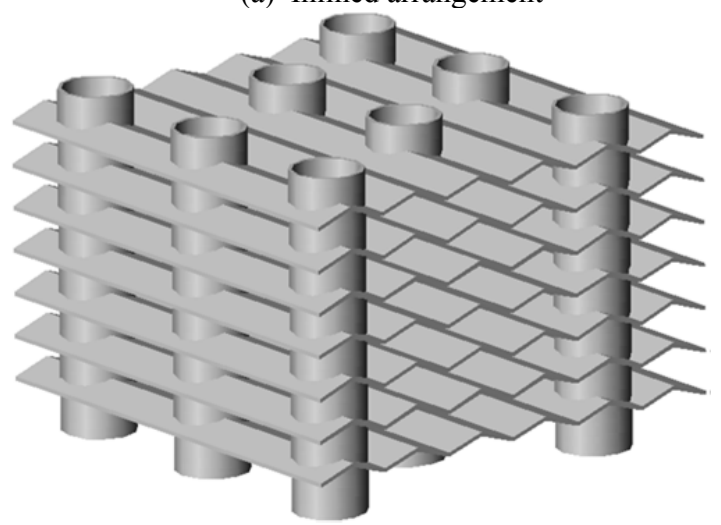

(b) Staggered arrangement

Fig. 1 Overview of typical wavy fin-and -tube heat exchanger model 

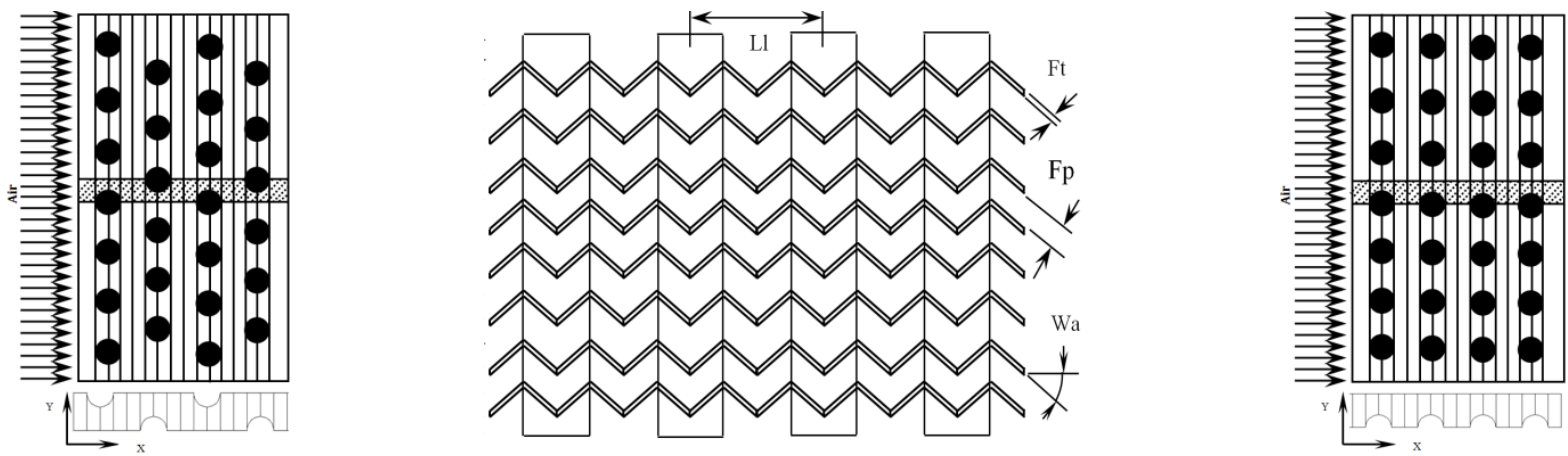

Fig. 2 Computational domain and co-ordinate system: staggered arrangement (left), in-lined arrangement (right), nomenclatures (middle)

Table 1. Geometric dimensions of heat exchanger model

\begin{tabular}{llll}
\hline Parameters & Symbols & Units & Dimensions \\
\hline Tube diameter & $\mathrm{D}$ & $(\mathrm{mm})$ & 9.525 \\
Longitudinal tube pitch & $\mathrm{Ll}$ & $(\mathrm{mm})$ & 19.05 \\
Transverse tube pitch & $\mathrm{Lt}$ & $(\mathrm{mm})$ & 25.40 \\
Fin Pitch & Fp & $(\mathrm{mm})$ & 3.530 \\
\hline
\end{tabular}

Simulation results for wavy fin considering staggered and inlined arrangements for turbulent $(2100 \leqslant \mathrm{Re} \leqslant 7000)$ flow range will be investigated to determine the effect on the heat transfer and pressure drop performance based on the available experimental data of Wang 1(Wang, Fu et al. 1997)and as a continuation of the numerical work of the author's for laminar flow (Bhuiyan, Islam et al. 2011) and transitional flow (Bhuiyan, Islam et al. 2012). Also a detailed analysis of the effect of those geometrical parameters mentioned above will be presented. Overall, a comprehensive parametric study considering longitudinal (Ll) (Lu, Huang et al. 2011), transverse (Lt) (Bhuiyan, Islam et al. 2011, Lu, Huang et al. 2011, Bhuiyan, Islam et al. 2012, Bhuiyan, Amin et al. 2012, Bhuiyan 2014), fin pitch (Fp) (Bhuiyan, Islam et al. 2011, Bhuiyan, Islam et al. 2012, Bhuiyan, Amin et al. 2012, Bhuiyan 2014) and wavy angle (Wa) (Bhuiyan, Islam et al. 2012, Glazar, Trp et al. 2012) has been carried out for staggered tube arrangement in a typical wavy heat exchanger using a commercial computational fluid dynamics code ANSYS CFX 12.0.

\section{MODEL DESCRIPTIONS}

\subsection{Physical model of the heat exchanger}

The objective of this study is to understand the hydrodynamics of flow and the corresponding heat transfer and pressure drop as a function of the longitudinal pitch (Ll), transverse pitch(Lt), fin pitch(Fp) and Wavy angle (Wa) in turbulent flow range. In this study, two different wavy fin and tube heat exchanger were considered for the simulations. These are: (i). Wavy fin staggered arrangement and (ii). Wavy fin inlined arrangement. The typical wavy fin and tube arrangements are shown in figure 1 . The detailed specifications of the selected heat exchanger are taken from the experimental work of Wang (Wang, Fu et al. 1997) as tabulated in Table 1. In brief, the computational domain for the present study is defined by $0 \leqslant X \leqslant 16.16 \mathrm{D}, 0 \leqslant \mathrm{Y} \leqslant 2.66 \mathrm{D}$ and $0 \leqslant \mathrm{Z} \leqslant 0.37 \mathrm{D}$, where tube diameter, $\mathrm{D}=9.525 \mathrm{~mm}$. The computational domain and the coordinate system are shown in figure 2 for the two configurations such as wavy fin staggered configuration (left) and Wavy fin In-lined configuration (right). The dashed line in the figure designates the computational domain. Three dimensional computational domain with detailed boundary condition is given in author's previous work given in Ref (Bhuiyan, A., A. Islam and M. Amin (2012). Assuming symmetry condition on the mid plane between the two fins, the bottom and the top boundaries simulate the fin and the mid-plane respectively. The nomenclatures used for the present computation and the parametric study are shown in the middle of the fig. 2.
Table 2. Cases considered for parametric study in turbulent flow range.

\begin{tabular}{cllll}
\hline Parameters & Units & Case-I & Case-II & Case-III \\
\hline Ll & $(\mathrm{mm})$ & 19.05 & 28.57 & 38.10 \\
Lt & $(\mathrm{mm})$ & 25.40 & 30.40 & 35.40 \\
Fp & $(\mathrm{mm})$ & 3.53 & 2.53 & 1.53 \\
Wa & $\left(^{\circ}\right)$ & 8 & 17 & 35 \\
\hline
\end{tabular}

\subsection{Boundary conditions}

The boundary conditions of the present study are described in the author's previous work (Bhuiyan 2010, Bhuiyan, Zaman et al. 2010, Bhuiyan, Islam et al. 2011, Bhuiyan, Islam et al. 2012, Bhuiyan, Amin et al. 2012, Bhuiyan 2014). The boundaries of the domain consist of inlet and outlet boundaries, symmetry planes and solid walls. The volume representing the air which passes through the gap between the two fins is extended downstream from the outlet of the last row cylinder of the heat exchanger for more accurate applications of boundary conditions that is to ensure a representative flow in the computational domain of the actual heat exchanger and to reduce the numerical oscillations (Reddy and Gartling 2010). A typical staggered tube arrangement domain with different boundary conditions is given in fig. 3 which represents the computational domain considered for the present investigation taken from (Bhuiyan, A., A. Islam and M. Amin (2012).

Inlet Boundary condition: The inlet boundary condition is representative to the experimental study considered for the numerical modeling in turbulent flow range. Based on the Reynolds number $\left(\mathrm{Re}_{\mathrm{H}}\right)$, at upstream boundary, uniform flow with constant velocity and constant temperature are assumed. This was considered to trigger the flow unsteadiness in the flow passage. In CFD, inlet flow field is applied normal to the inlet face of the computational domain. Other velocity components are assumed to be zero. A constant temperature of $25^{\circ} \mathrm{C}$ is set at the flow inlet to meet the room air conditions.

Wall boundary condition: No-slip boundary condition is used at the fins and the tube surfaces. These surfaces are assumed to be solid wall with no slip boundary condition and constant wall temperature $T_{\text {wall }}$ set to $100^{\circ} \mathrm{C}$. The fins and tubes are assumed to be made of aluminium. At symmetric wall, no-slip boundary condition is used with constant wall temperature. In this study, turbulent flow is considered having Reynolds number in the range of $2100 \leqslant \mathrm{Re}_{\mathrm{H}} \leqslant 7000$.

Outlet boundary condition: At the outlet, stream wise gradient (Neumann boundary conditions) for all the variables are set to zero for all the cases considered. As mentioned earlier, the computational domain is extended up to seven times of the tube diameter from the last tube column. Though, the full computational domain is not shown in the present paper. This is considered only to avoid or reduce numerical oscillation. It can be concluded that the computational domain is long enough in the flow direction for the flow and thermal field to be fully developed. 


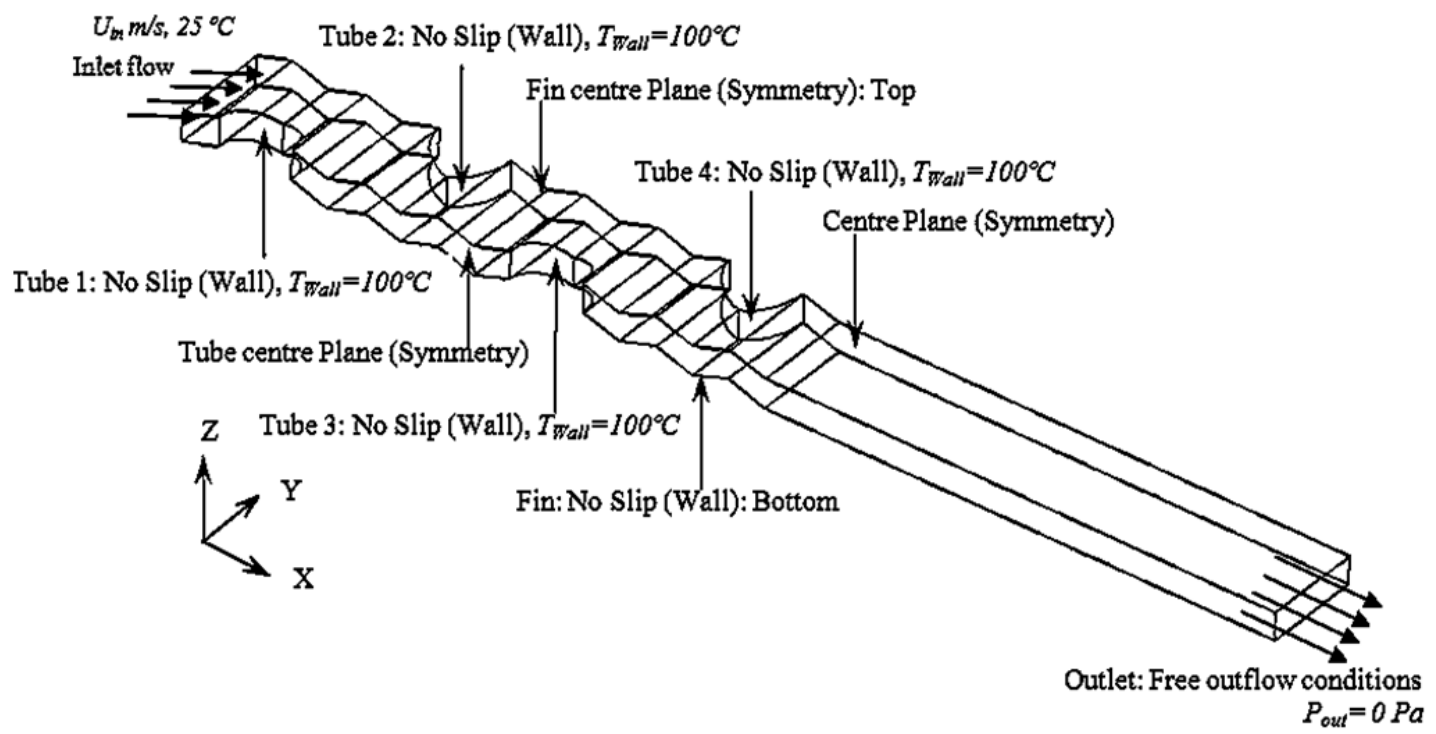

Fig. 3 A typical 3D computational domain with different boundary conditions (for Laminar flow) considered in the present study.

\subsection{Investigated cases}

As the main objective of this study is to investigate the effects of different geometric parameter on the overall performance of the heat exchanger, a detail parametric study has been conducted for turbulent flow range. For parametric study, three different cases are considered for a specific geometric parameter such as $\mathrm{Lt}, \mathrm{Lt}, \mathrm{Fp}$ and $\mathrm{Wa}$ as of previous (Bhuiyan, Islam et al. 2011, Bhuiyan, Islam et al. 2012, Bhuiyan, Amin et al. 2012, Bhuiyan 2014) and given in Table 2. Table 1 represents the baseline case of the study where wavy angle is assumed equal to $17^{\circ}$. All other parameters were kept constant as baseline case when one parameter changing from case 1 to case 3 .

\section{COMPUTATIONAL METHODOLOGY}

\subsection{Mathematical modelling}

The numerical simulations of the fin-tube heat exchanger were conducted for turbulent $(2100 \leq \mathrm{ReH} \leq 7000)$ case. 3D Navier-Stokes equations (Sohr 2012) were considered for the simulation of flow and heat transfer and energy equation for steady incompressible fluid with constant properties. The flow is described by the conservation laws for mass (continuity), momentum (Navier-Stokes) and by the energy equations are as follows (Hossain and Naser 2011, Bhuiyan and Naser 2014, Bhuiyan and Naser 2015):

$\frac{\partial \mathrm{u}_{\mathrm{i}}}{\partial \mathrm{x}_{\mathrm{i}}}=0$

$\rho\left(\frac{\partial \mathrm{u}_{\mathrm{i}}}{\partial \mathrm{t}}+\mathrm{u}_{\mathrm{j}} \frac{\partial \mathrm{u}_{\mathrm{i}}}{\partial \mathrm{x}_{\mathrm{j}}}\right)=-\frac{\partial \mathrm{p}}{\partial \mathrm{x}_{\mathrm{i}}}+\frac{\partial}{\partial \mathrm{x}_{\mathrm{j}}}\left[\left(\mu+\mu_{\mathrm{T}}\right)\left(\frac{\partial \mathrm{u}_{\mathrm{i}}}{\partial \mathrm{x}_{\mathrm{j}}}+\frac{\partial \mathrm{u}_{\mathrm{j}}}{\partial \mathrm{x}_{\mathrm{i}}}\right)\right]+\rho \mathrm{g}_{\mathrm{i}}$

$\rho C_{p}\left(\frac{\partial T}{\partial t}+u_{j} \frac{\partial T}{\partial x_{j}}\right)=\frac{\partial}{\partial x_{j}}\left[\left(\lambda+\frac{\mu_{T} C_{p}}{\operatorname{Pr}_{T}}\right) \frac{\partial T}{\partial x_{j}}\right]$

As suggested by Yuan (Yuan 2000), $\operatorname{Pr}_{\mathrm{T}}=0.9$ was used in the current study. The value of $\mu_{\mathrm{T}}$ is determined based on the specific turbulence model that is being used. In $\mathrm{k}-\omega$ turbulent model the $\mu_{\mathrm{T}}$ is linked to the turbulence kinetic energy $(\mathrm{k})$ and turbulence frequency $(\omega)$. In this study, k- $\omega$ turbulence model is employed. Details of different turbulent models are documented in literature (Menter 1994, Panse 2005, Reddy and Gartling 2010). One of the advantages of the $k-\omega$ formulation is the near wall treatment for low Reynolds number computations. The model does not involve the complex non-linear wall treatment for low Reynolds number computations. The model does not involve the complex non-linear damping functions required for the $\mathrm{k}-\varepsilon$ model as is therefore more accurate and more robust. A low Reynolds k- $\varepsilon$ model would typically require a near wall resolution of $\mathrm{y}^{+}<2$, while a low Reynolds number $\mathrm{k}-\omega$ model would require at least $\mathrm{y}^{+}<2$, where $\mathrm{y}^{+}$is the non-dimensional near wall spacing. In industrial flows, even $\mathrm{y}^{+}<2$ cannot be guaranteed in most applications and for this reason; a new near wall treatment was developed for the $\mathrm{k}-\omega$ models. It allows for smooth shift from a low Reynolds number form to a wall function formulation. Details of the used k- $\oplus$ turbulent models are documented in literature (Menter 1994, Yang, Asako et al. 1997, Reddy and Gartling 2010, Amin and Ramachandran 2011). More details about the mathematical formulations considered in this study are documented in (Yuan 2000, Bhuiyan 2010, Bhuiyan, Zaman et al. 2010, Bhuiyan, Islam et al. 2011, Bhuiyan, Islam et al. 2012, Bhuiyan, Amin et al. 2012, Bhuiyan 2014).

\subsection{Numerical descriptions}

The commercial computational fluid dynamics code ANSYS CFX-12 was employed to carry out the numerical investigation. ICEM CFD, a meshing tool of ANSYS CFX was used to mesh the computational domain. FVM (Islam, Amin et al. 2009, Bhuiyan and Naser 2015, Bhuiyan and Naser 2015) was used in this CFD code. This code uses a coupled solver, which solves the hydrodynamic equations as a single system. For steady state problems, the time-step behaves like an acceleration parameter, which is responsible to guide the approximate solutions in a physically based manner to a steady state solution. In order to attain the desired accuracy it is recommended to define a target variable that will monitor the numerical error. The typical range used for the present convergence of the computation is about $1 \mathrm{e}^{-4}$ which is good enough for these types of simulations. The maximum number of iteration applied for the present investigation is 1000 and convergence is monitored and ensured by the following steps: (i) reduction of residuals by a pre-specified level and plotting of the residuals, (ii). Plotting the max residuals with iteration number, (iii). Plotting the target variables as function of iteration number or residual level.

Table 3: Different grid resolutions for the wavy fin configurations

\begin{tabular}{ccc}
\hline Grid test & No of nodes & No of elements \\
\hline Test 1 & 364722 & 890238 \\
Test $2 *$ & 549669 & 1355049 \\
Test 3 & 789954 & 2080026
\end{tabular}

*-used in present study. 

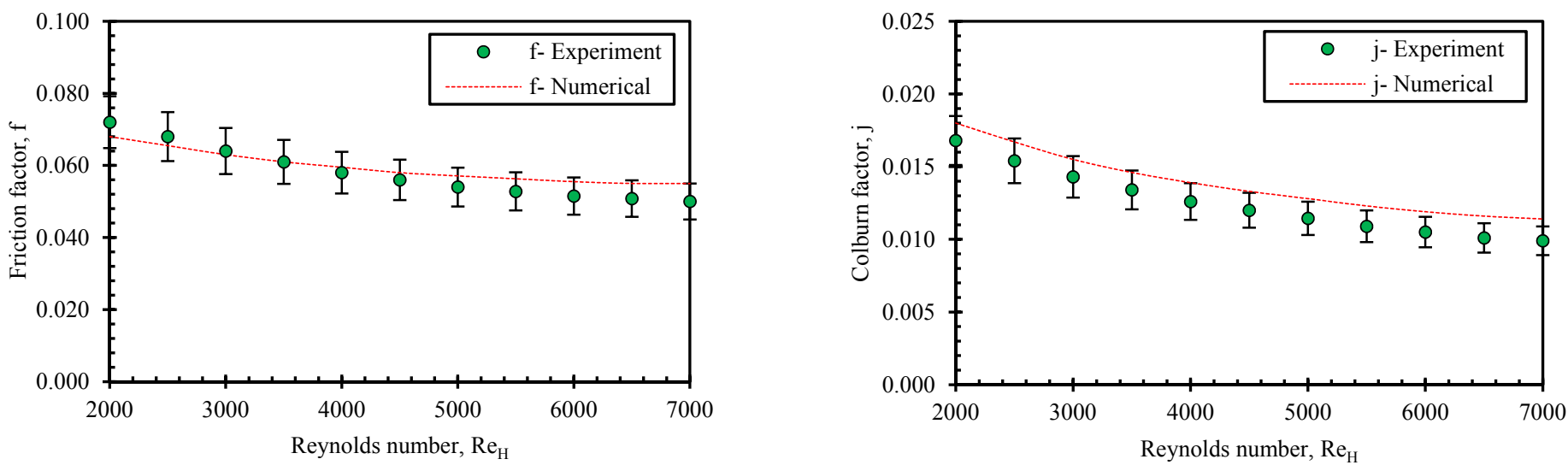

Fig. 4 Comparison of numerical prediction with the experimental data for (a). Friction factor (f) and (b). Colburn factor (j)

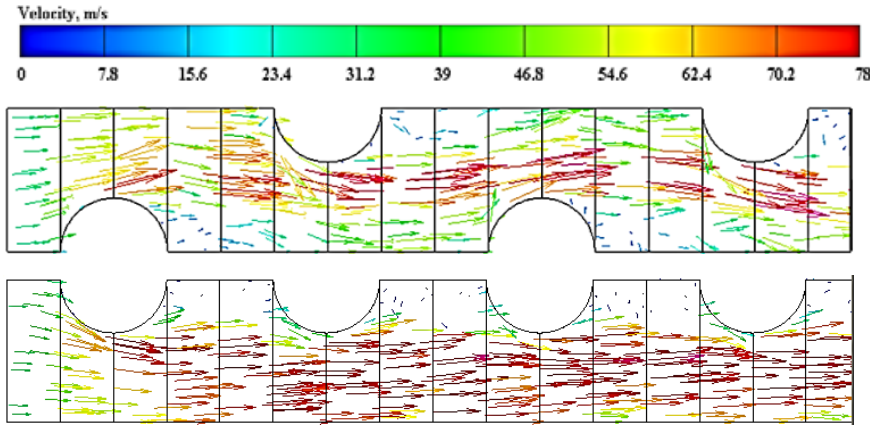

Fig. 5 Comparison of velocity $(\mathrm{m} / \mathrm{s})$ distribution for different tube arrangement at $\mathrm{Re}_{\mathrm{H}}=7000$

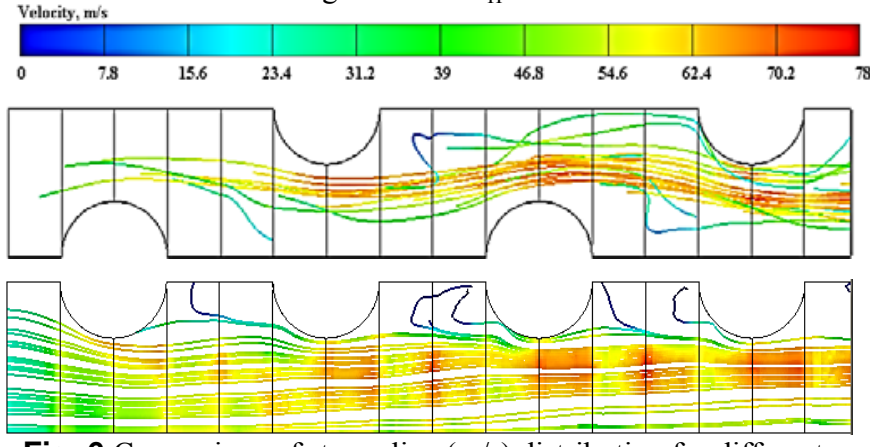

Fig. 6 Comparison of streamline $(\mathrm{m} / \mathrm{s})$ distribution for different tube arrangement at $\mathrm{Re}_{\mathrm{H}}=7000$

\subsection{Grid systems}

Grid sensitivity test is required to attain a desired level of accuracy with minimum computational time. Grid sensitivity tests with three different grid sizes were conducted to develop the acceptability of the computation. Grid was denser in the region of the tubes as the pressure, temperature and the velocity gradients increases with the flow. A comprehensive grid independency test is carried out presented in author's previous paper (Bhuiyan, Islam et al. 2012) and the grid having 183223 nodes with 451683 elements is chosen for laminar and transitional flow ranges. However, in this turbulent flow range, the maximum Reynolds number used is more than three times higher than the one used in authors' previous studies, so the grid must be different as well, and a new grid convergence study must be carried out: the higher the Reynolds number, the higher the gradients, and the finer the grid. In order to consider this effect, a new grid test is considered in this study with several times higher grid and convergence results were obtained. In this study, grid having 549669 nodes with 1355049 elements is chosen for transitional flow ranges. The statistics of the different grid used in the present study are given in Table 3.

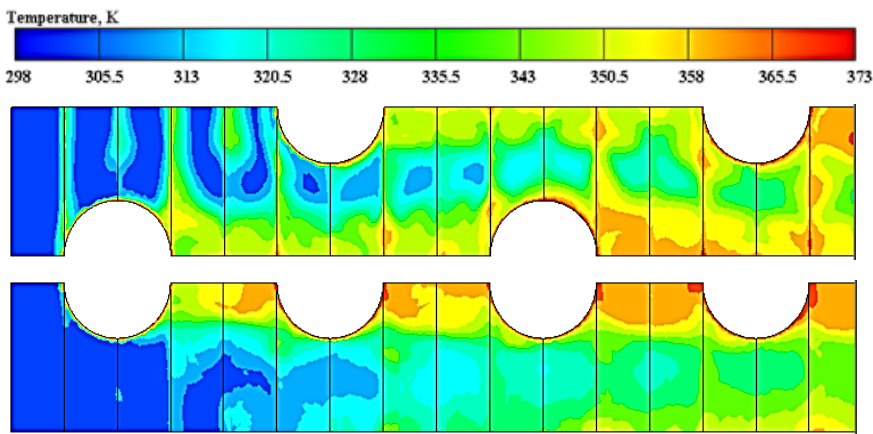

Fig. 7 Comparison of temperature (K) distribution for different tube arrangement at $\mathrm{Re}_{\mathrm{H}}=7000$

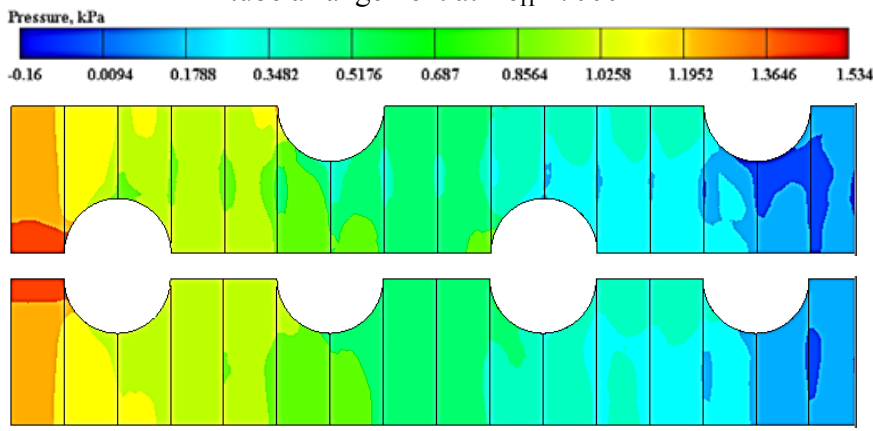

Fig. 8 Comparison of pressure $(\mathrm{kPa})$ distribution for different tube arrangement at $\mathrm{Re}_{\mathrm{H}}=7000$

\subsection{Validation}

In order to attain the confidence about the numerical result, a comprehensive validation study was conducted considering the similar conditions as in the experimental work considered in Ref. (Wang, Fu et al. 1997). To ensure the numerical results are reliable, calculations were first prepared to scrutinize the recital of fin geometry having 4 rows staggered circular tube configuration with the experimental data by Wang et al. (Wang, Fu et al. 1997). The detailed geometry of the examined heat exchanger is same as (Wang, Fu et al. 1997). The accuracy of the study was established by comparing the values for friction factor (f) and Colburn factor (j) by Wang et al. (Wang, Fu et al. 1997) with the present numerical modelling for turbulent flow range. Figure 4 shows the Comparison of numerical prediction with the experimental data for (a). Friction factor (f) and (b). Colburn factor (j) (Dotted line represents the numerical data \& coloured filled point shows the experimental data extracted). To show the comparison between numerical and experimental data, a 10\% error bar is set on the experimental values. From both the plots, the discrepancy is found within $10 \%$ in error range. The graphical presentation is shown in fig. 3 


\section{RESULT AND DISCUSSION}

\subsection{Flow variation in different tube arrangements}

In wavy fin tube arrangements, flow interruption is generally caused by two constructive features such as the wavy corrugation and the tubes position. It is expected that the flow will maintain a re-orientation at each of the wavy corrugation starts. This phenomenon is responsible for less flow recirculation in the wake of the tubes. In order to differentiate among the inlined and staggered tube arrangement, flow velocity and streamline contours is presented in fig. 5 \& 6 respectively. It is noticed that flow disruption proceeds on both sides of the computational structure for staggered configuration. As there are repeated disruptions of the flow direction because of tubes on both sides of the structure, comparatively less recirculation is detected. But for in-lined arrangements stream is congested only on one side of the heat exchanger as all the tubes are on one side. There are two flow regions can be observed such as free flow regions and the stagnant flow regions. This result contents the response of variation of recirculation zone. The temperature and pressure distribution for different tube arrangement are shown in figures $7 \& 8$ respectively. Similar behavior is observed as the streamline pattern and the velocity vector. It is seen from the temperature profile of in-lined arrangements, there is high temperature zones in the trailing edge of the tubes can be called warm zones because of the recirculation flow which stretches between two adjacent tubes. Figure 9 represents the flow characteristics for different tube arrangements in turbulent flow range compared with the laminar (Bhuiyan, Islam et al. 2011)and transitional (Bhuiyan, Islam et al. 2012) flow ranges. There is a definite variation of staggered and in-lined tube arrangement presented here. Comparatively higher heat transfer and pressured drop is observed in all flow ranges in staggered case. Though $\mathrm{f}$ and $\mathrm{j}$ both are lower in in-lined arrangement but higher efficiency is found in in-lined case. It is seen that the tube engagements play a vigorous role in the heat transfer and pressure drop features. In staggered arrangements, improved flow mixing is witnessed due to staggered tube designs and thus delivers higher heat transfer and pressure drop physiognomies than the in-lined arrangements. So wavy staggered configuration will be considered to investigate the effect of different geometrical parameter in the turbulent range.
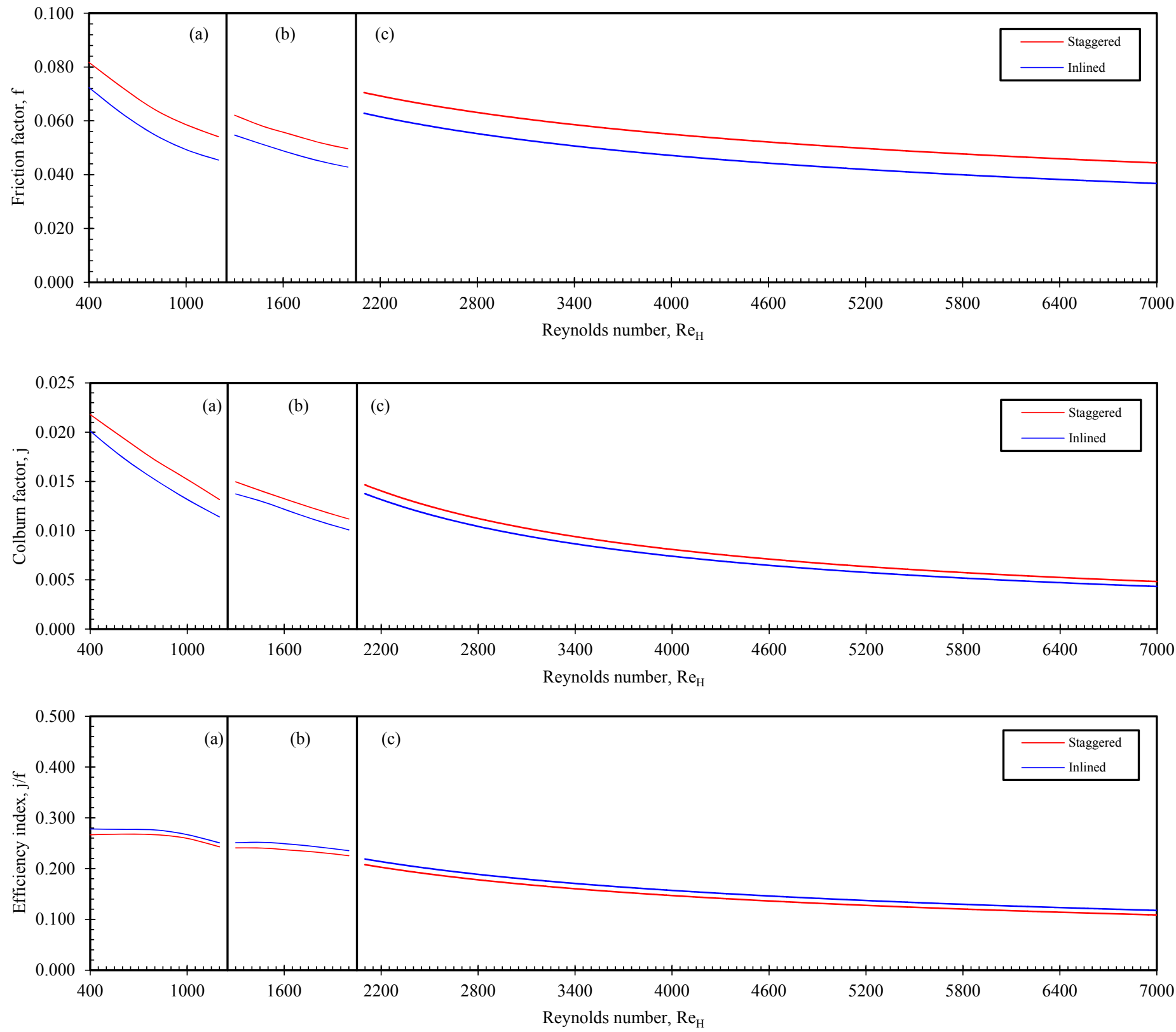

Fig. 9 Flow characteristics for different tube arrangement in (c). Turbulent flow range $\left(2100 \leqslant \operatorname{Re}_{\mathrm{H}} \leqslant 7000\right)$ compared with the published

(a). Laminar flow range $\left(400 \leqslant \mathrm{Re}_{\mathrm{H}} \leqslant 1200\right)$ and (b). Transitional flow range $\left(1300 \leqslant \mathrm{Re}_{\mathrm{H}} \leqslant 2000\right)$ 

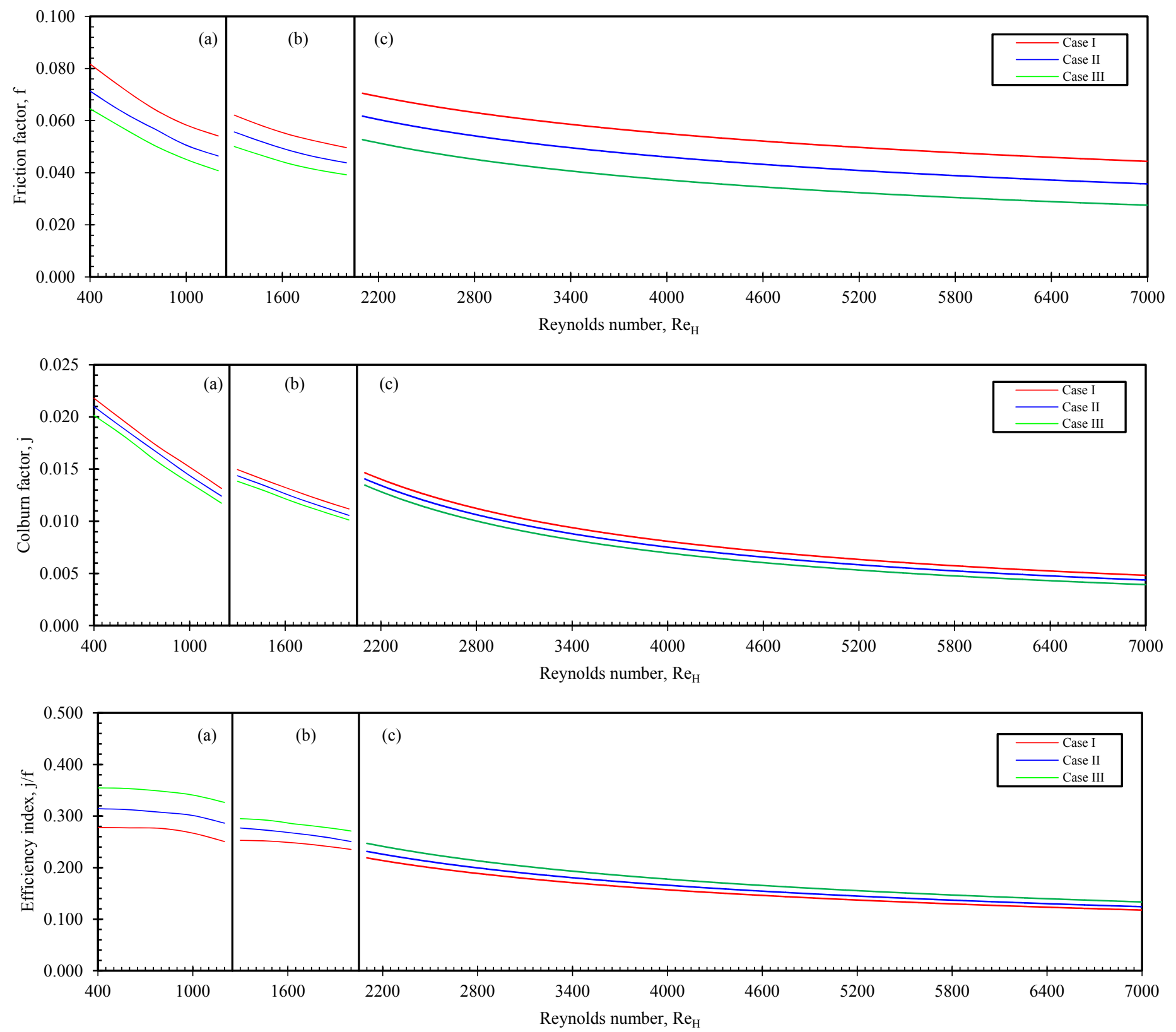

Fig. 10 Flow characteristics for the variation of different longitudinal pitches (Ll) for staggered tube arrangement in (c). Turbulent flow range (2100 $\left.\leqslant \operatorname{Re}_{\mathrm{H}} \leqslant 7000\right)$ compared with the published (a). Laminar flow range $\left(400 \leqslant \mathrm{Re}_{\mathrm{H}} \leqslant 1200\right)(\mathrm{b})$. Transitional flow range (1300 $\left.\leqslant \mathrm{Re}_{\mathrm{H}} \leqslant 2000\right)$.

\subsection{Effect of Longitudinal Pitches (LI)}

Flow characteristics for the variation of different longitudinal tube pitch (L1) such as $19.05 \mathrm{~mm}, 28.575 \mathrm{~mm}$ and $38.10 \mathrm{~mm}$ in turbulent flow range are presented in figure 10. Also the comparisons with the laminar and transitional range are critically evaluated. It is found that with the increase of $\mathrm{Ll}$, friction factor (f) and Colburn factor (j) decrease, but efficiency index increases. With the increase of $\mathrm{Ll}$ from $19.05 \mathrm{~mm}$ to $28.575 \mathrm{~mm}$ and $28.575 \mathrm{~mm}$ to $38.10 \mathrm{~mm}$, f decreases $19.54 \%$ and $15.84 \%$ while $\mathrm{j}$ decreases $4.83 \%$ and $5.07 \%$ respectively in the turbulent range. This statement can be explained that higher the longitudinal pitch (Ll) the surface area is also increased. So the flow is freer and the airflow becomes distributed results in lower friction factor. The same behavior as $\mathrm{f}$ is found for heat transfer. In general, the increase in the heat transfer area would increase the heat transfer. But the current findings contradict this phenomenon. This can be explained that lower the longitudinal pitch, flow is more restricted and the airflow is dense due to close tube spacing and this enhance the heat transfer.
But the rate of increase in friction factor is higher than the Colburn factor and as a result the efficiency decrease with the decrease of Ll. But in laminar and transitional range, $\mathrm{f}$ increases $12.83 \%$ and $11.05 \%$ while $\mathrm{j}$ increases $4.20 \%$ and $4.55 \%$ respectively for the change of 19.05 $\mathrm{mm}$ to $28.575 \mathrm{~mm}$. But for $28.575 \mathrm{~mm}$ to $38.10 \mathrm{~mm}$ pitch increase, $\mathrm{f}$ increase $10.50 \%$ and $10.33 \%$, while $\mathrm{j}$ changes $4.56 \%$ and $3.86 \%$ for laminar and transitional flow ranges respectively. Efficiency index increases $10 \%$ and $12 \%$ for the increase of $\mathrm{Ll}$ of $19.05 \mathrm{~mm}$ to $28.575 \mathrm{~mm}$ respectively. But it was seen previously that for laminar case this change was found as $9.74 \%$ and $6.67 \%$ while for transitional case, these change was observed as $7.3 \%$ and $7.2 \%$ respectively. While comparing the flow model, for laminar to transitional change, f increase $16.61 \%$ and $14.91 \%$ and $14.75 \%$ for the three longitudinal pitch cases respectively. But for the case of $\mathrm{j}$, these changes are more significant. The change is around $25 \%$ in all cases. But for transitional to turbulent shift, f decrease $18.95 \%, 15.6 \%$ and $8.52 \%$ for the selected case. But the change is nominal in these two flow changes. 

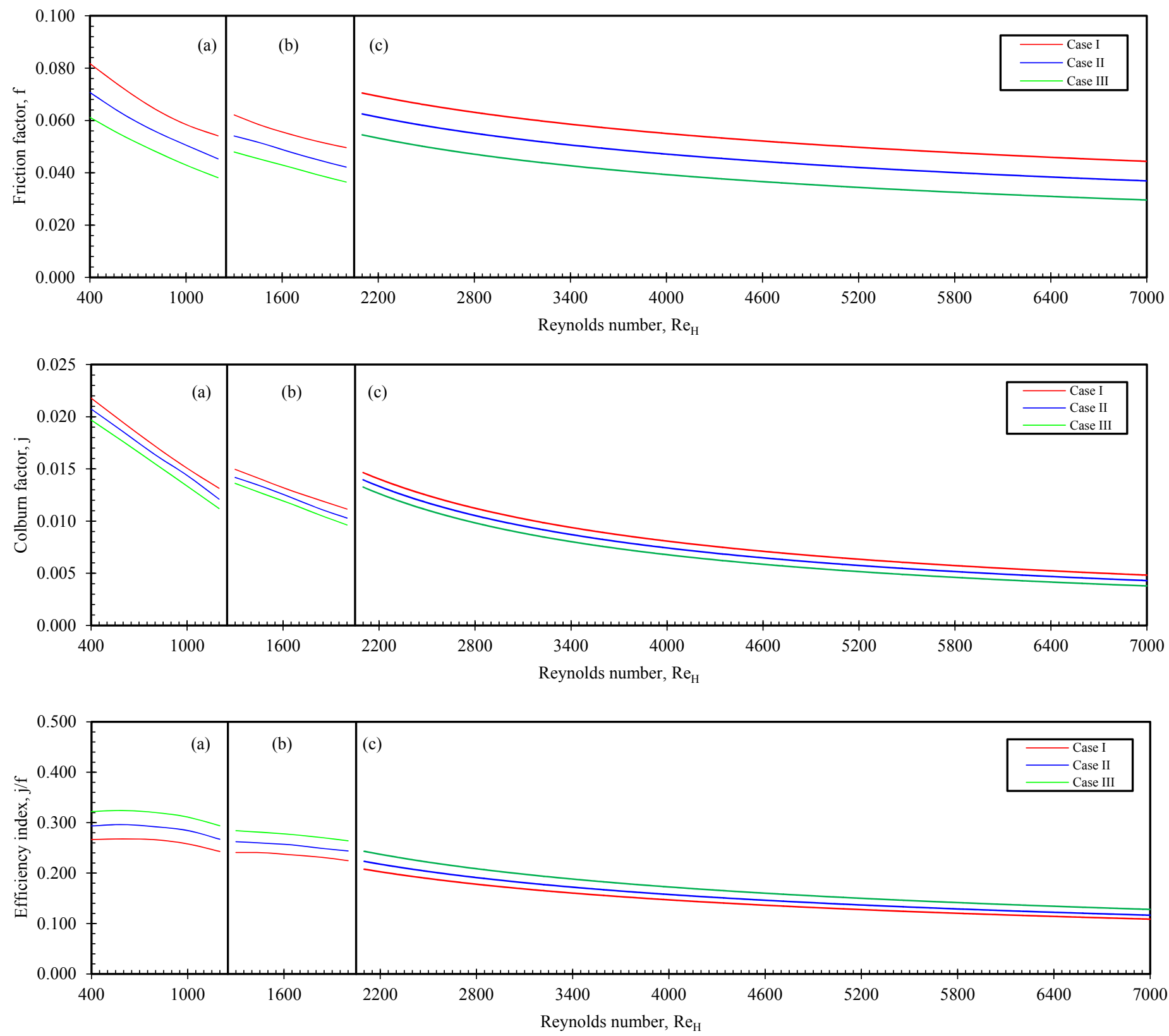

Fig. 11 Flow characteristics for the variation of different transverse pitches (Lt) for staggered tube arrangement in (c). Turbulent flow range (2100 $\left.\leqslant \mathrm{Re}_{\mathrm{H}} \leqslant 7000\right)$ compared with the published (a). Laminar flow range (400 $\left.\leqslant \operatorname{Re}_{\mathrm{H}} \leqslant 1200\right)(\mathrm{b})$. Transitional flow range (1300 $\left.\leqslant \mathrm{Re}_{\mathrm{H}} \leqslant 2000\right)$

\subsection{Effect of Transverse Pitches (Lt)}

Flow characteristics for the variation of different transverse pitches (Lt) for staggered tube arrangement in turbulent flow range compared with the published laminar (Bhuiyan, Islam et al. 2011) and transitional flow range (Bhuiyan, Islam et al. 2012) is presented in this study. The effects of transverse pitch (Lt) on the pressure drop and heat transfer and efficiency for the staggered arrangements are shown in fig. 11. The effect is very much similar to that of longitudinal pitch. For the increase of $\mathrm{Lt}$ from $25.4 \mathrm{~mm}$ to $30.4 \mathrm{~mm}$, f decrease $13.9 \%, 13.04 \%$ and $12.17 \%$ while $\mathrm{j}$ decrease $5.1 \%, 5.8 \%$ and $5.63 \%$ for laminar, transitional and turbulent flow ranges respectively. For the increase of Lt from $30.4 \mathrm{~mm}$ to $35.4 \mathrm{~mm}$, f decrease $14.12 \%, 12.31 \%$ and $13.86 \%$ while $\mathrm{j}$ decrease $5.82 \%, 5.05 \%$ and $5.97 \%$ for laminar, transitional and turbulent flow ranges respectively. Though $\mathrm{f}$ and $\mathrm{j}$ decrease with the increase of $\mathrm{Lt}$, but $\mathrm{j} / \mathrm{f}$ increase. The increase found as $10.12 \%, 8.28 \%$ and $7.39 \%$ for first set and $9.63 \%, 8.26 \%$ and $9.10 \%$ for the second set of $\mathrm{Lt}$ in the laminar, transitional and turbulent flow ranges respectively. While comparing the flow model, for laminar to transitional change, f increases $16.61 \%$, $15.75 \%$ and $13.98 \%$ for the three cases respectively. The value of $\mathrm{j}$ changes $24.97 .5 \%, 25.47 \%$ and $24.86 \%$ respectively. While comparing laminar to transitional change, f decrease $18.86 \%, 20.04 \%$ and $17.93 \%$ but the value of $\mathrm{j}$ changes $4.45 \%, 4.28 \%$ and $5.21 \%$ respectively. The effect of transverse pitch can be explained similar to longitudinal pitch effect but different value. With the increase of transverse pitch, the surface area is increased. So the flow area is expanded and hence the airflow becomes distributed corresponds to lower pressure drop. The same behavior as $f$ is found for heat transfer. This can be explained that lower the transverse pitch, flow is more restricted and the airflow is dense due to close tube spacing and this enhance the heat transfer. Though similar performance is observed for longitudinal as well as transverse pitch in terms of heat transfer and pressure drop performance, but the efficiency shows a variation for respective cases. This justifies the significance of variation of different pitches. 

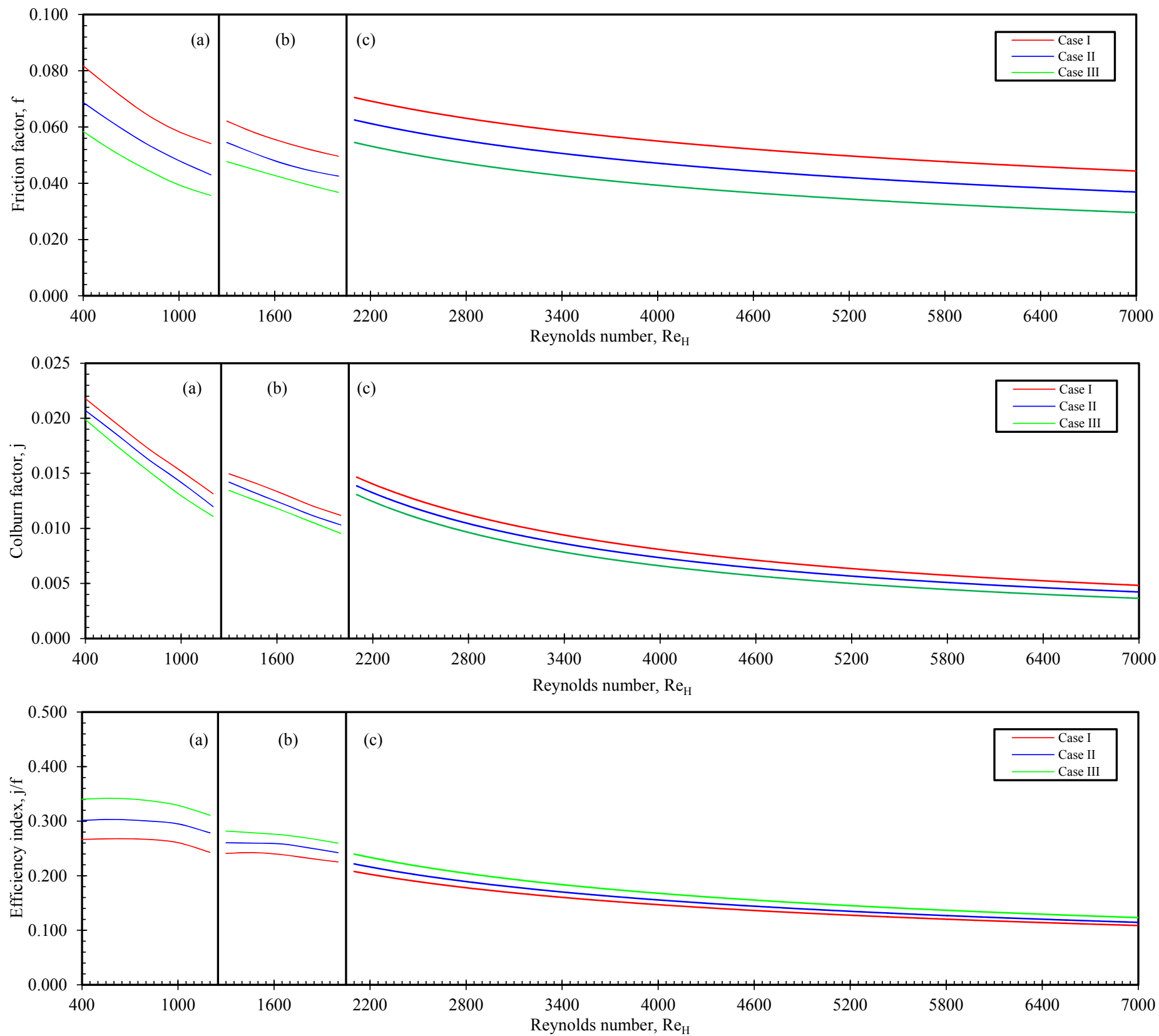

Fig. 12 Flow characteristics for the variation of three different fin pitch (Fp) for staggered tube arrangement in (c). Turbulent flow range (2100 $\leqslant$ $\left.\operatorname{Re}_{\mathrm{H}} \leqslant 7000\right)$ compared with the published (a). Laminar flow range $\left(400 \leqslant \mathrm{Re}_{\mathrm{H}} \leqslant 1200\right)$, (b). Transitional flow range $\left(1300 \leqslant \mathrm{Re}_{\mathrm{H}} \leqslant 2000\right)$

\subsection{Effect of Fin Pitches (Fp)}

Flow characteristics for the variation of different fin pitches $(\mathrm{Fp})$ for staggered tube arrangement in turbulent flow range compared with the published laminar (Bhuiyan, Islam et al. 2011) and transitional flow range (Bhuiyan, Islam et al. 2012) is presented in figure 12. With the decrease of Fp, friction factor and Colburn factor both decreases but $j / f$ increases. Heat transfer performance is quite similar as the pressure drop. This is because when Fp is reduced the flow becomes more streamlined resulting in better flow mixing. Also reduction in the Fp reduces the tube surface area which affects the pressure drop performance. This can also be explained on the basis of boundary layer concept. The boundary layer interruption could not have occurred at large fin pitches with faster inlet air velocities. Therefore, the heat transfers for high Reynolds Number were independent of the pitches. However for, smaller fin pitch range with lower inlet velocities, the heat transfer and pressure drop decreased with a reduction in fin pitches.
This is because the interruption of the boundary layers between the fins resulted from an increase in the boundary layer thickness with a reduction in fin pitches. The enhancement of the $j$-factor with fin pitches may be the result of the delay of the boundary layer interruption to the next row. But the behavior is fully different with the characteristics found for $\mathrm{Ll}$ and $\mathrm{Lt}$ Cases. For the decrease of Fp from $3.53 \mathrm{~mm}$ to $2.53 \mathrm{~mm}$, f decrease $17.07 \%, 13.42 \%$ and $12.17 \%$ while $\mathrm{j}$ decrease $6.0 \%, 6.59 \%$ and $6.44 \%$ for laminar, transitional and turbulent flow ranges respectively. For the decrease of Fp from 2.53 $\mathrm{mm}$ to $1.53 \mathrm{~mm}$, f decrease $16.50 \%, 12.07 \%$ and $13.86 \%$ while $\mathrm{j}$ decrease $6.16 \%, 5.62 \%$ and $6.88 \%$ for laminar, transitional and turbulent flow ranges respectively. For laminar to transitional change, $\mathrm{f}$ increase $16.55 \%$ and $12.87 \%$ and $8.20 \%$ for the three fin pitch cases respectively. The value of $\mathrm{j}$ changes $24.5 \%, 25.23 \%$ and $24.79 \%$ respectively. For transitional to turbulent shift, f decrease $18.86 \%$, $20.57 \%$ and $18.05 \%$ for the three fin pitch cases respectively. The value of $\mathrm{j}$ changes $4.88 \%, 4.72 \%$ and $5.99 \%$ respectively. 

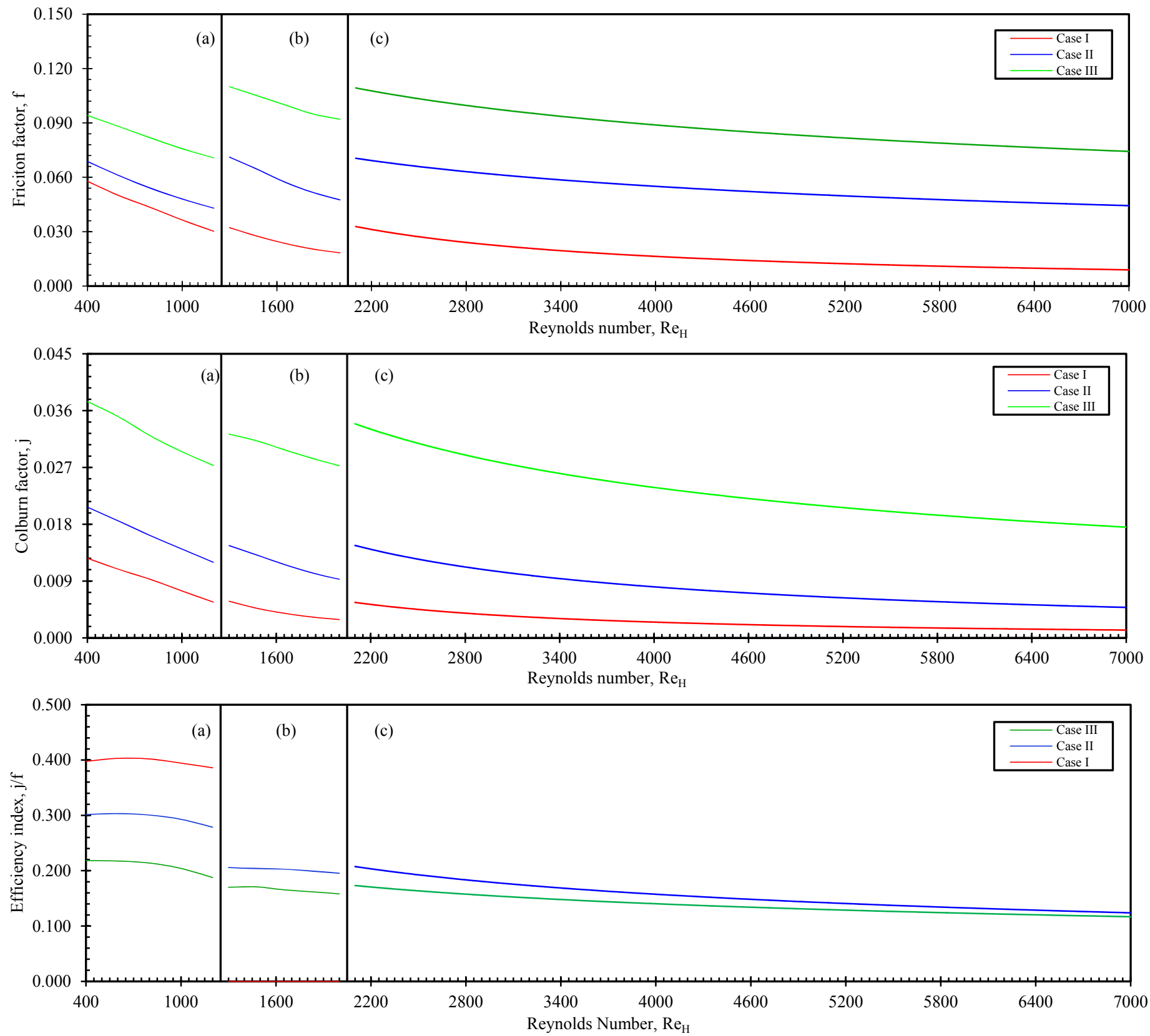

Fig. 13 Flow characteristics for the variation of three different wavy angles (Wa) for staggered tube arrangement in (c). Turbulent flow range (2100 $\left.\leqslant \mathrm{Re}_{\mathrm{H}} \leqslant 7000\right)$ compared with the published (a). Laminar flow range $\left(400 \leqslant \mathrm{Re}_{\mathrm{H}} \leqslant 1200\right)$, (b). Transitional flow range $\left(1300 \leqslant \mathrm{Re}_{\mathrm{H}} \leqslant 2000\right)$.

\subsection{Effect of Wavy Angles (Wa)}

Wavy angle (Wa) is one of the important parameters in the design of heat exchanger of wavy type. Little attention has given on the performance of different wavy angle in the literature. Figure 13 shows the flow characteristics for the variation of three different wavy angles (Wa) for staggered tube arrangement in turbulent flow range $(2100<$ $\left.\mathrm{Re}_{\mathrm{H}}<7000\right)$ compared with the published laminar flow range $\left(400<\mathrm{Re}_{\mathrm{H}}\right.$ $<1200)$ (Bhuiyan, Islam et al. 2011) and transitional flow range $(1300<$ $\mathrm{Re}_{\mathrm{H}}<2000$ ) (Bhuiyan, Islam et al. 2012). It is found that with the increase of wavy angle, heat transfer and pressure drop increases drastically. But efficiency curves shows opposite trends. For the increase of $\mathrm{Wa}$ from $8^{\circ}$ to $17.5^{\circ}$ and $17.5^{\circ}$ to $35^{\circ}$, heat transfer and pressure drop increases more than $50 \%$ in each cases. While comparing the flow model, for laminar to transitional change, f decreases $43.92 \%$ for wavy angle $8^{\circ}$, while for transitional to turbulent case, it increases $11.0 \%$.

\section{CONCLUSION}

This numerical study has been conducted as a continuation of author's previous work considering wavy fin and tube heat exchanger. Commercial CFD Code is employed, coupled with user defined program. Code was validated with experimental results from literature and a reasonable matching has been observed. Simulated results were presented for turbulent flow range comparing previously published laminar and transitional flow ranges. There is clear difference in the performance of staggered and in-lined tube arrangement. Comparatively better performance is observed in staggered case. Detailed parametric study is carried out considering important pitches and wavy angles. The trend observed in turbulent flow is in line with the laminar and transitional flows. This parametric study provides a clear understanding and guideline for the design of similar type of heat exchanger depending upon requirements. 


\section{NOMENCLATURES}

$\begin{array}{lll}\mathrm{C}_{\mathrm{P}} & {[\mathrm{J} / \mathrm{kg} \mathrm{K}]} & \text { Specific heat } \\ \mathrm{D} & {[\mathrm{m}]} & \text { Tube diameter } \\ \mathrm{F}_{\mathrm{p}} & {[\mathrm{m}]} & \text { Fin pitch } \\ \mathrm{F}_{\mathrm{t}} & {[\mathrm{m}]} & \text { Fin thickness } \\ \mathrm{H} & {[\mathrm{m}]} & \text { Fin spacing } \\ \mathrm{h} & {\left[\mathrm{W} / \mathrm{m}^{2} \mathrm{~K}\right]} & \text { Heat transfer coefficient } \\ \mathrm{k} & {\left[\mathrm{m}^{2} / \mathrm{s}^{2}\right]} & \text { Kinetic energy } \\ \mathrm{L} & {[\mathrm{m}]} & \text { Flow length } \\ \mathrm{Ll} & {[\mathrm{m}]} & \text { longitudinal tube pitch } \\ \mathrm{Lt} & {[\mathrm{m}]} & \text { Transverse tube pitch } \\ \mathrm{m} & {[\mathrm{kg} / \mathrm{s}]} & \text { Mass flow rate } \\ \mathrm{P} & {[\mathrm{Pa}]} & \text { Local pressure } \\ \mathrm{P}_{\text {in }} & {[\mathrm{Pa}]} & \text { Inlet pressure } \\ \mathrm{P}_{\mathrm{k}} & {\left[\mathrm{kg} / \mathrm{m}^{3} \mathrm{~s}^{3}\right]} & \text { Share production } \\ \mathrm{T} & {\left[{ }^{\circ} \mathrm{C}\right]} & \text { Temperature } \\ \mathrm{T}_{\text {in }} & {\left[{ }^{\circ} \mathrm{C}\right]} & \text { Inlet temperature } \\ \mathrm{T}_{\mathrm{Wall}} & {\left[{ }^{\circ} \mathrm{C}\right]} & \text { Wall temperature } \\ \mathrm{U} & {[\mathrm{m} / \mathrm{s}]} & \text { Velocity } \\ \mathrm{u}_{\text {in }} & {[\mathrm{m} / \mathrm{s}]} & \text { Inlet(frontal) velocity } \\ \varepsilon & {\left[\mathrm{m} / \mathrm{s}^{3}\right]} & \text { Turbulence dissipation } \\ \lambda & {[\mathrm{W} / \mathrm{m} \cdot \mathrm{K}]} & \text { Thermal conductivity } \\ \mu & {\left[\mathrm{Ns} / \mathrm{m}^{2}\right]} & \text { Dynamic viscosity } \\ \mu_{\mathrm{T}} & {\left[\mathrm{Ns} / \mathrm{m}^{2}\right]} & \text { Turbulent viscosity } \\ \rho & {\left[\mathrm{kg} / \mathrm{m}^{3}\right]} & \text { Fluid density } \\ \omega & {\left[\mathrm{s}^{-1}\right]} & \text { Turbulent frequency } \\ \mathrm{f} & & \text { Friction factor } \\ \mathrm{j} & & \text { Colburn factor } \\ \mathrm{Pr} & & \text { Prandtl Number } \\ \mathrm{Re} & & \text { Reynolds number } \\ & & \end{array}$

\section{REFERENCES}

Amin, M. R., and Ramachandran, S. K., 2011, "Numerical Analysis of Airside Characteristics in Plain and Wavy Heat Exchangers in the Turbulent Flow Regime", ASME 2011 International Mechanical Engineering Congress and Exposition, American Society of Mechanical Engineers, 10 (Heat and Mass Transport Processes, Parts A and B): 97107.

http://dx.doi.org/10.1115/IMECE2011-62330

Bhuiyan, A. A., Islam, A. K. M. S., and Amin, M. R., 2012, "Numerical Study of 3D Thermal and Hydraulic Characteristics of Wavy Fin-andTube Heat Exchanger," Frontiers in Heat and Mass Transfer (FHMT), 3(3).

http://dx.doi.org/10.5098/hmt.v3.3.3006

Bhuiyan, A. A., Amin, M. R., and Islam, A. K. M. S., 2012, "ThreeDimensional Performance Analysis of Plain Fin Tube Heat Exchangers in Transitional Regime," Applied Thermal Engineering, 50(1): 445-454. http://dx.doi.org/10.1016/j.applthermaleng.2012.07.034

Bhuiyan, A. A., Amin, M. R., Karim, M. R., and Islam, A. K. M. S., 2014, "Plate Fin and Tube Heat Exchanger Modeling: Effects of Performance Parameters for Turbulent Flow Regime," International Journal of Automotive and Mechanical Engineering 9(1): 1768-1781. http://dx.doi.org/10.15282/ijame.9.2013.25.0147

Bhuiyan, A. A., Islam, A. K. M. S., and Amin, M. R., 2011, "Numerical Prediction of Laminar Characteristics of Fluid Flow and Heat Transfer in Finned-Tube Heat Exchangers," Innovative Systems Design and Engineering 2(6): 1-12.

Bhuiyan, A. A., Islam, A. K. M. S., 2010, “A Numerical Investigation on Heat Transfer and Pressure Drop Performance of Typical Wavy Fin-
and-Tube Heat Exchanger," The 7th Jordanian International Mechanical Engineering Conference (JIMEC'7), Jordan.

Bhuiyan, A. A., and Naser, J., 2014, Effect of Recycled Ratio on Heat Transfer Performance of Coal Combustion in a $0.5 \mathrm{MWth}$ Combustion Test Facility, 19th Australasian Fluid Mechanics Conference, Melbourne, Austraia.

Bhuiyan, A. A., and Naser, J., 2015, "Computational Modelling of Cofiring of Biomass with Coal under Oxy-fuel Condition in a Small Scale Furnace," Fuel, 143(0): 455-466.

http://dx.doi.org/10.1016/j.fuel.2014.11.089

Bhuiyan, A. A., and Naser, J., 2015, "Numerical Modelling of Oxy Fuel Combustion, the Effect of Radiative and Convective Heat Transfer and Burnout," Fuel, 139(0): 268-284.

http://dx.doi.org/10.1016/j.fuel.2014.08.034

Bhuiyan, A. A., and Naser, J., 2015, "Numerical Modeling of Biomass Co-combustion with Pulverized Coal in a Small Scale Furnace," Procedia Engineering, 105(C): 509-516.

http://dx.doi.org/10.1016/j.proeng.2015.05.083

Bhuiyan, A. A., and Naser, J., 2015, "Modeling of Slagging in Industrial Furnace: A Comprehensive Review," Procedia Engineering, 105(C): 517-524.

http://dx.doi.org/10.1016/j.proeng.2015.05.084

Bhuiyan, A. A., Zaman, R. I., and Islam, A. K. M. S., 2010, "Numerical Analysis of Thermal and Hydraulic Performance of Fin and Tube Heat Exchangers," 13th Asian Congress of Fluid Mechanics (13ACFM), Bangladesh Society of Mechanical Engineers(BSME).

Chu, P., He, Y. L., Lei, Y. G., Tian, L. T., and Li, R., 2009, "ThreeDimensional Numerical Study on Fin-and-oval-tube Heat Exchanger with Longitudinal Vortex Generators," Applied Thermal Engineering, 29(5-6): 859-876.

http://dx.doi.org/10.1016/j.applthermaleng.2008.04.021

Dong, J., Chen, Q., and Wei, W., 2012, "Experimental Investigation and Comparison on Fin Surfaces Performance of Flat Tube Heat Exchangers," Advanced Materials Research, 354-355: 389-393. http://dx.doi.org/10.4028/www.scientific.net/AMR.354-355.389

Dong, J., Su, L., Chen, Q., and Xu, W., 2013, "Experimental Study on Thermal-Hydraulic Performance of a Wavy Fin-and-Flat Tube Aluminum Heat Exchanger," Applied Thermal Engineering, 51(1-2): 32-39.

http://dx.doi.org/10.1016/j.applthermaleng.2012.09.018

Du, X., Feng, L., Yang, Y., and Yang, L., 2013, "Experimental Study on Heat Transfer Enhancement of Wavy Finned Flat Tube with Longitudinal Vortex Generators," Applied Thermal Engineering, 50(1): 55-62.

http://dx.doi.org/10.1016/j.applthermaleng.2012.05.024

Glazar, V., Trp, A., and Lenic, K., 2012, "Numerical Study of Heat Transfer and Analysis of Optimal Fin Pitch in a Wavy Fin-and-Tube Heat Exchanger," Heat Transfer Engineering, 33(2): 88-96. http://dx.doi.org/10.1080/01457632.2011.589312

Gong, J., Min, C., Qi, C., Wang, E., and Tian, L., 2013, "Numerical Simulation of Flow and Heat Transfer Characteristics in Wavy Fin-andTube Heat Exchanger with Combined Longitudinal Vortex Generators," International Communications in Heat and Mass Transfer, 43: 53-56. http://dx.doi.org/10.1016/j.icheatmasstransfer.2013.01.004 
He, Y. L., Chu, P., Tao, W. Q., Zhang, Y. W., and Xie, T., 2013, "Analysis of Heat Transfer and Pressure Drop for Fin-and-Tube Heat Exchangers with Rectangular Winglet-type Vortex Generators," Applied Thermal Engineering, 61(2): 770-783.

http://dx.doi.org/10.1016/j.applthermaleng.2012.02.040

Hossain, A., Naser, J., and Imteaz, H., 2011, "Extended analytical turbulent diffusion model for particle dispersion and deposition in a horizontal pipe: comparison with CFD simulation," Environmental Modeling \& Assessment, 16(3): 295-311.

http://dx.doi.org/10.1007/s10666-010-9248-9

Islam, A. K. M. S., Amin, M. R., Barna, S. F., Bhuiyan, A. A., and Banna, M. H., 2009, "Mixed Convection and Entropy Generation Characteristics Inside a Porous Cavity With Viscous Dissipation Effect," ASME 2009 International Mechanical Engineering Congress and Exposition, American Society of Mechanical Engineers, 9(Heat Transfer, Fluid Flows, and Thermal Systems, Parts A, B and C): 533542.

http://dx.doi.org/10.1115/IMECE2009-10883

Jang, J. Y., and Chen, L. K., 1997, "Numerical Analysis of Heat Transfer and Fluid Flow in a Three-Dimensional Wavy-Fin and Tube Heat Exchanger," International Journal of Heat and Mass Transfer, 40(16): 3981-3990.

http://dx.doi.org/10.1016/S0017-9310(97)00047-1

Junqi, D., Jiangping, C., Zhijiu, C., Yimin, Z., and Wenfeng, Z., 2007, "Heat Transfer and Pressure Drop Correlations for the Wavy Fin and Flat Tube Heat Exchangers," Applied Thermal Engineering, 27(11-12): 2066-2073.

http://dx.doi.org/10.1016/j.applthermaleng.2006.11.012

Kim, N. H., Ham, J. H., and Cho, J. P., 2008, "Experimental Investigation on the Airside Performance of Fin-and-Tube Heat Exchangers having Herringbone Wave Fins and Proposal of a New Heat Transfer and Pressure Drop Correlation," Journal of Mechanical Science and Technology, 22(3): 545-555.

http://dx.doi.org/10.1007/s12206-007-1116-4

Kim, N. H., Youn, J. H., and Webb, R. L., 1996, "Heat Transfer and Friction Correlations for Wavy Plate Fin-and-Tube Heat Exchangers," American Society of Mechanical Engineers, Heat Transfer Division, (Publication) HTD, 330: 43-52.

http://dx.doi.org/10.1115/1.2824141

Lin, Z. M., Wang, L. B., and Zhang, Y. H., 2014, "Numerical Study on Heat Transfer Enhancement of Circular Tube Bank Fin Heat Exchanger with Interrupted Annular Groove Fin," Applied Thermal Engineering, 73(2): 1465-1476..

http://dx.doi.org/10.1016/j.applthermaleng.2014.05.073

Lu, C. W., Huang, J. M., Nien, W., and Wang, C. C., 2011, "A Numerical Investigation of the Geometric Effects on the Performance of Plate Finned-Tube Heat Exchanger," Energy Conversion and Management, 52(3): 1638-1643.

http://dx.doi.org/10.1016/j.enconman.2010.10.026

Menter, F. R., 1994, "Two-equation eddy-viscosity turbulence models for engineering applications," AIAA journal, 32(8): 1598-1605.

http://dx.doi.org/10.2514/3.12149

Panse, S., 2005, "A Numerical Investigation of Thermal and Hydraulic Characteristics in 3D Plate and Wavy Fin-Tube Heat Exchangers for Laminar and Transitional Flow Regimes," M. Sc. Thesis, Montana State University, Bozeman, Montana, USA.
Pirompugd, W., Wongwises, S., and Wang, C. C., 2006, "Simultaneous Heat and Mass Transfer Characteristics for Wavy Fin-and-Tube Heat Exchangers under Dehumidifying Conditions," International Journal of Heat and Mass Transfer, 49(1-2): 132-143.

http://dx.doi.org/10.1016/j.ijheatmasstransfer.2005.05.043

Reddy, J. N., and Gartling, D. K., 2010, "The finite element method in heat transfer and fluid dynamics," CRC press.

Sohr, H., 2012, "The Navier-Stokes equations: An elementary functional analytic approach," Springer.

Tao, Y. B., He, Y. L., Huang, J., Wu, Z. G., and Tao, W. Q., 2007, "Three-Dimensional Numerical Study of Wavy Fin-and-Tube Heat Exchangers and Field Synergy Principle Analysis," International Journal of Heat and Mass Transfer, 50(5-6): 1163-1175.

http://dx.doi.org/10.1016/j.ijheatmasstransfer.2006.03.019

Tao, Y. B., He, Y. L., Wu, Z. G., and Tao, W. Q., 2007, "Numerical Design of an Efficient Wavy Fin Surface Based on the Local Heat Transfer Coefficient Study," Journal of Enhanced Heat Transfer, 14(4): 315-332.

http://dx.doi.org/10.1615/JEnhHeatTransf.v14.i4.50

Wang, C. C., 1999, "Investigation of Wavy Fin-and-Tube Heat Exchangers: A Contribution to Databank," Experimental Heat Transfer, 12(1): 73-89.

http://dx.doi.org/10.1080/089161599269825

Wang, C., Fu, W., and Chang, C., 1997, "Heat Transfer and Friction Characteristics of Typical Wavy Fin-and-Tube Heat Exchangers," Experimental Thermal and Fluid Science, 14(2): 174-186. http://dx.doi.org/10.1016/S0894-1777(96)00056-8

Wang, C. C., Hwang, Y. M., and Lin, Y. T., 2002, "Empirical Correlations for Heat Transfer and Flow Friction Characteristics of Herringbone Wavy Fin-and-Tube Heat Exchangers," International Journal of Refrigeration, 25(5): 673-680.

http://dx.doi.org/10.1016/S0140-7007(01)00049-4

Wang, C. C., Liaw, J. S., and Yang, B. C., 2011, "Airside Performance of Herringbone Wavy Fin-and-Tube Heat Exchangers - Data with Larger Diameter Tube," International Journal of Heat and Mass Transfer, 54(5-6): 1024-1029.

http://dx.doi.org/10.1016/j.ijheatmasstransfer.2010.11.038

Wu, Y., Wu, M., Zhang, Y., and Wang, L., 2014, "Experimental Study of Heat and Mass Transfer of a Rolling Wheel," Heat and Mass Transfer/Waerme- und Stoffuebertragung, 50(2): 151-159.

http://dx.doi.org/10.1007/s00231-013-1228-6

Yan, W. M., and Sheen, P. J., 2000, "Heat Transfer and Friction Characteristics of Fin-and-Tube Heat Exchangers," International Journal of Heat and Mass Transfer, 43(9): 1651-1659.

http://dx.doi.org/10.1016/S0017-9310(99)00229-X

Yang, L. C., Asako, Y., Yamaguchi, Y., and Faghri, M., 1997, "Numerical Prediction of Transitional Characteristics of Flow and Heat Transfer in a Corrugated Duct," Journal of Heat Transfer, 119(1): 6269.

http://dx.doi.org/10.1115/1.2824101

Yuan, Z., 2000, "Numerical Study of Periodically Turbulent Flow and Heat Transfer in a Channel with Transverse Fin Arrays," International Journal of Numerical Methods for Heat \& Fluid Flow, 10(8): 842-861. http://dx.doi.org/10.1108/09615530010359139 